\title{
Quantification of spatial metal accumulation patterns in Noccaea caerulescens by X-ray fluorescence image processing for genetic studies
}

Lucas van der Zee ${ }^{1}$, Amelia Corzo Remigio ${ }^{3}$, Lachlan W. Casey ${ }^{4}$, Imam Purwadi ${ }^{3}$, Jitpanu Yamjabok², Antony van der Ent $^{3}$, Gert Kootstra ${ }^{1 *}$ and Mark G. M. Aarts ${ }^{2 *}$ (1)

\begin{abstract}
Background: Hyperaccumulation of trace elements is a rare trait among plants which is being investigated to advance our understanding of the regulation of metal accumulation and applications in phytotechnologies. Noccaea caerulescens (Brassicaceae) is an intensively studied hyperaccumulator model plant capable of attaining extremely high tissue concentrations of zinc and nickel with substantial genetic variation at the population-level. Micro-X-ray Fluorescence spectroscopy ( $\mu$ XRF) mapping is a sensitive high-resolution technique to obtain information of the spatial distribution of the plant metallome in hydrated samples. We used laboratory-based $\mu$ XRF to characterize a collection of 86 genetically diverse Noccaea caerulescens accessions from across Europe. We developed an imageprocessing method to segment different plant substructures in the $\mu X R F$ images. We introduced the concentration quotient (CQ) to quantify spatial patterns of metal accumulation and linked that to genetic variation.
\end{abstract}

Results: Image processing resulted in automated segmentation of $\mu$ XRF plant images into petiole, leaf margin, leaf interveinal and leaf vasculature substructures. The harmonic means of recall and precision (F1 score) were $0.79,0.80$, 0.67 , and 0.68 , respectively. Spatial metal accumulation as determined by CQ is highly heritable in Noccaea caerulescens for all substructures, with broad-sense heritability $\left(\mathrm{H}^{2}\right)$ ranging from 76 to $92 \%$, and correlates only weakly with other heritable traits. Insertion of noise into the image segmentation algorithm barely decreases heritability scores of $\mathrm{CQ}$ for the segmented substructures, illustrating the robustness of the trait and the quantification method. Very low heritability was found for CQ if randomly generated substructures were compared, validating the approach.

Conclusions: A strategy for segmenting $\mu \mathrm{XRF}$ images of Noccaea caerulescens is proposed and the concentration quotient is developed to provide a quantitative measure of metal accumulation pattern, which can be used to determine genetic variation for such pattern. The metric is robust to segmentation error and provides reliable $\mathrm{H}^{2}$ estimates. This strategy provides an avenue for quantifying XRF data for analysis of the genetics of metal distribution patterns in plants and the subsequent discovery of new genes that regulate metal homeostasis and sequestration in plants.

Keywords: Metal hyperaccumulation, $\mu X R F$, Imaging, Image segmentation, Noccaea caerulescens, Heritability

*Correspondence: gert.kootstra@wur.nl; mark.aarts@wur.nl

${ }^{1}$ Farm Technology, Department of Plant Sciences, Wageningen University and Research, Wageningen, The Netherlands

${ }^{2}$ Laboratory of Genetics, Department of Plant Sciences, Wageningen University and Research, Wageningen, The Netherlands

Full list of author information is available at the end of the article

\section{Background}

Understanding the mechanism of metal accumulation in plants is of great importance. Large areas of the world are enriched with potentially toxic trace elements, either for 
anthropogenic reasons, such as metal mining and smelting, or for natural, geochemical reasons. Increased exposure of humans to certain metals affects human health, including an increased risk of cancer [1-3]. Most metals that affect human health also have a negative effect on plants. There are, however, some plant species that are extremely tolerant to metal exposure and that hyperaccumulate certain trace elements to very high concentrations in their leaves. Hyper accumulating species can be used to extract certain metals and metalloids from the soil [4], either to clean the soil, a process called phytoremediation, or even to extract valuable metals from soils containing sub-economic concentrations without disrupting the topsoil in a process called phytomining [5, 6]. Hyperaccumulator plants also take up trace elements essential for human health, such as iron (Fe), zinc ( $\mathrm{Zn})$, manganese $(\mathrm{Mn})$ or copper $(\mathrm{Cu})$. By understanding the plant physiology and the underlying genetics of metal accumulation, cultivars can be bred that contain higher contents of these micronutrients in their edible parts, which will benefit their nutritional value. Such biofortified cultivars can help fight mineral malnutrition, one of the major causes of human mortality worldwide [7]. To unlock these applications of metal accumulation, an improved understanding of the underlying genetics is required.

Noccaea caerulescens is a particularly interesting species to study in this regard. It can accumulate and tolerate extraordinary concentrations of $\mathrm{Zn}$, cadmium $(\mathrm{Cd})$, and nickel $(\mathrm{Ni})$ [8], and some accessions even lead $(\mathrm{Pb})$. Moreover, there is substantial variation in metal accumulation genotype and phenotype between different populations of this species [8-10]. Several genes are known to participate in metal hyperaccumulation. These include genes for metal influx transporters that take up metals into the cytosol $[11,12]$, for metal tonoplast transporters, which transport metals and their chelators to and from the vacuole $[13,14]$, for metal efflux transporters, which exclude excess metals from the cytosol and are involved in transportation towards the shoot [12], and for a range of regulatory and signalling proteins [15]. Yet many genes remain to be uncovered to gain a full understanding of metal accumulation.

While total metal concentrations are routinely obtained using destructive sample analysis techniques, such as Inductively Coupled Plasma Atomic Emission Spectroscopy/Mass Spectrometry (ICP-AES/MS), more complex phenotypic traits remain underexplored, such as the spatial distribution of the metallome across plant tissues. Previous work on metal distribution was limited to mostly qualitative analysis. For instance, leaf tip $\mathrm{Zn}$ accumulation and a homogenous leaf distribution of $\mathrm{Ni}$ was found using laser ablation inductively coupled plasma mass spectroscopy [16]. Fluorescent probes were used in combination with microscopy to find that $\mathrm{Zn}$ accumulation is not affected by plant age, that phosphorous concentration decreases upon $\mathrm{Zn}$ accumulation in older plants and that $\mathrm{Zn}$ mainly locates to the apoplastic space of leaf epidermal cells [17]. Spatial accumulation patterns were found not to differ between plants grown in a natural environment versus those grown hydroponically [18]. Finally, the use of synchotron-based X-ray fluorescence microscopy on the closely related Noccaea tymphaea uncovered that $\mathrm{Zn}$ and $\mathrm{Ni}$ do not necessarily colocalize in Noccaea [19]. Overall, these studies lack the comparison of metal accumulation distribution phenotypes across many accessions. Image-processing and elemental mapping methods will enable discrimination between traits that are specific to the accessions and those that hold for the whole species. Also, it will allow for the determination of genetic heritability of metal distribution patterns which can lead to the discovery of novel genes and processes that regulate metal homeostasis.

$\mathrm{X}$-ray Fluorescence Spectroscopy is a non-destructive elemental analysis technique that is capable of detecting a wide range of elements covering most of the plant metallome $[20,21]$. Micro X-ray Fluorescence $(\mu \mathrm{XRF})$ uses an X-ray source to illuminate a sample enabling mapping fresh or hydrated plant specimens with a spatial resolution as small as $1 \mu \mathrm{m}$ and a detection limit as low as $5 \mu \mathrm{g} \mathrm{g}^{-1}$ for transition metals [22]. $\mu \mathrm{XRF}$ is singularly suited for such applications, as it is a non-destructive method for obtaining quantitative spatial information of elemental distribution in physically intact biological materials that avoids introducing artefacts associated with standard sample preparation protocols, such as sectioning and fixation [23].

When initially viewing $\mu \mathrm{XRF}$ scans of different accessions of Noccaea caerulescens, differences were observed in the spatial distribution of metals in leaves, the petiole, leaf margin, leaf vasculature and leaf interveinal substructures (Fig. 1). The petiole anatomically consists largely of vascular bundles and hence the XRF signal would be dominated by elements that concentrate in the phloem (given that xylem is typically dilute). Based on physiological knowledge, differences between petiole and leaf blade vascular bundles are therefore expected to be small. To test these qualitative observations, substructures must be segmented by classifying each pixel of the image as belonging to the background or one of the substructure classes. Image-processing techniques can segment images into regions representing these substructures by considering characteristics of their shape and/or pixel intensities. Every pixel in the image can be classified to belong to a certain substructure. A complete review of machine-vision algorithms for plant-part segmentation is out of the scope of this article, but some relevant 


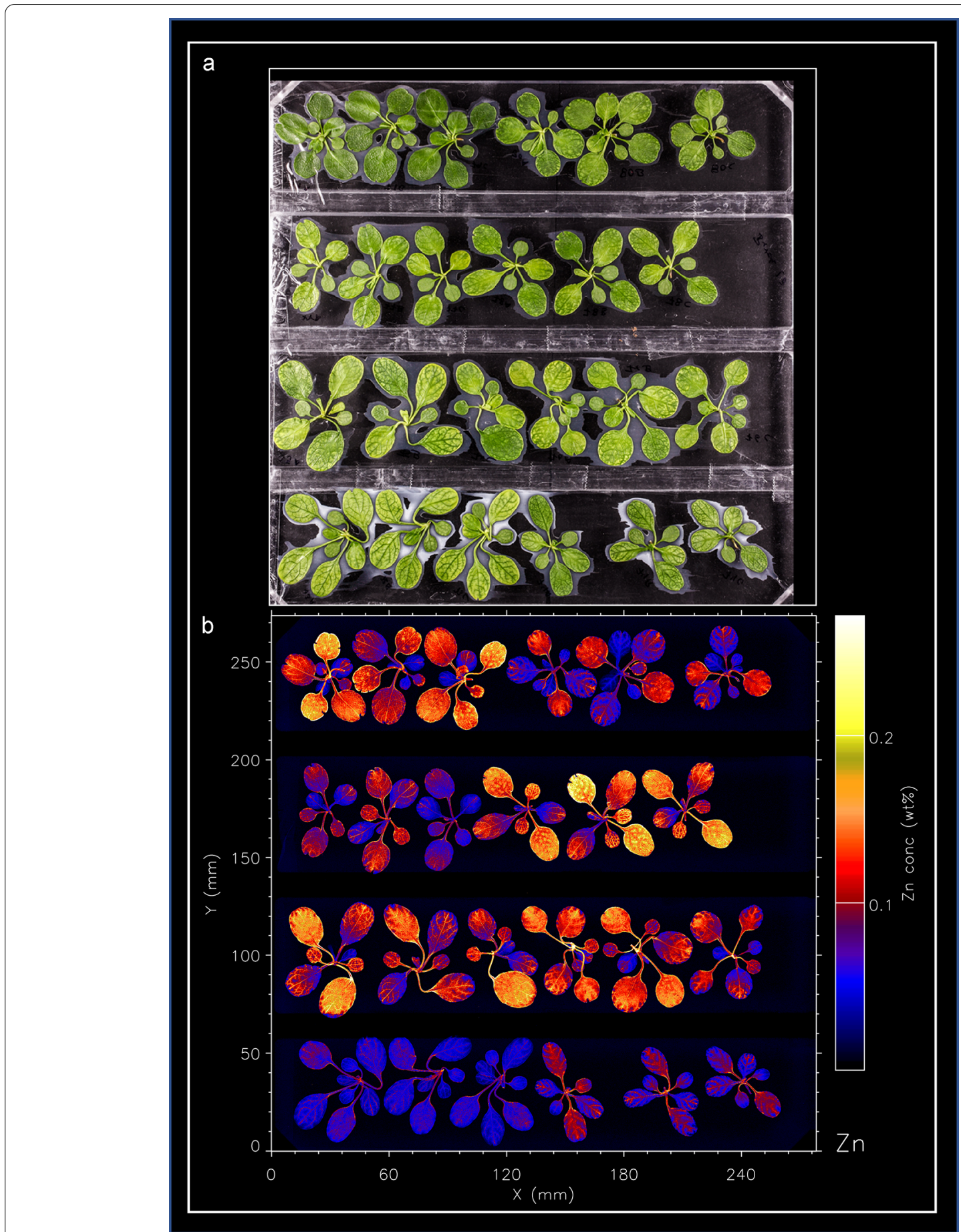

Fig. 1 A batch of 24 N. caerulescens plants, corresponding to three plants of eight accessions, grouped together per accession, imaged by a photography, and $\mathbf{b}$ processing of the $\mu$ XRF scan to visualize Zn concentration as a false-colour image, with black corresponding to the lowest and white to the highest $\mathrm{Zn}$ concentrations

examples are described below. Thresholding is often used to extract an object from a uniform background based on the pixel intensity or colour $[24,25]$ Instead of using a static threshold, dynamic thresholding techniques, such as Otsu thresholding or local thresholding, make the algorithm more robust to variations in illumination. A leaf can be subdivided in different substructures using classical image-processing techniques. For instance, 
morphological opening can be used to segment the petiole from the blade [26]. Leaf margins can be detected using the morphological gradient operation to mark an edge of arbitrary width along the foreground mask of the leaf [27]. Vasculature can be detected based on their small width using morphological opening [24, 28]. Leaf vasculature has also been separated from the leaf tissue based on pixel intensities [25]. Alternatively, edgedetection algorithms based on the second-order image derivative, such as the Laplacian operator, have been used to identify vasculature [29]. Lastly, 'Artificial Ants' have been used too to segment the vasculature by tracing edges [30,31]. Active-contour methods form another set of image-processing techniques that allow the detection of plant parts $[32,33]$. In recent years, deep-learning techniques have become popular for plant-part segmentation, e.g., [34-36]. These methods, however, require a lot of training data. For this study, a method based on classical image-processing techniques shows to be more effective. Our method uses intensity thresholding to segment the plant from the background. Blade and petiole are separated using morphological opening. The leaf margin is found through a morphological gradient operation, and finally, the leaf vasculature and interveinal tissue are separated using a Laplacian operator.

The objective of this study is to develop a method to quantify the spatial distribution of metal accumulation in different plant substructures and to determine the broadsense heritability of these metal distribution phenotypes. To this end, we have spatially mapped the metallome by $\mu \mathrm{XRF}$ in a diversity panel of different $N$. caerulescens accessions grown in a hydroponic nutrient solution enriched in $\mathrm{Zn}$ and $\mathrm{Ni}$. We propose an image-processing method to segment the $\mu \mathrm{XRF}$ images of $N$. caerulescens into four different substructures (petiole, leaf margin, leaf interveinal and leaf vasculature). Consecutively, we introduce a numerical description of spatial metal distribution, the concentration quotient (CQ), which is used to determine the heritability of spatial metal distributions across the $N$. caerulescens diversity panel. While data are obtained for the whole metallome, the analysis focuses exclusively on the two elements supplied in excess, $\mathrm{Zn}$ and $\mathrm{Ni}$, and two general, abundant elements, $\mathrm{K}$ and $\mathrm{Ca}$.

\section{Results}

\section{Metal distribution in the plants}

The Noccaea caerulescens accessions are grown in batches of eight accessions each, in hydroponics, with five plants per accession. The three best growing plants are used for $\mu \mathrm{XRF}$ analysis. The three plants per accession are highly comparable in plant size and appearance, between accessions there is considerable variation, reflecting the genetic variation that is expected for a diversity panel of accessions originating from the north-west of Spain to the south of Finland (see Additional file 1). After 1 week of hydroponic growth at $2 \mu \mathrm{M} \mathrm{Zn}$ and no Ni, plants are supplied with fresh solution containing $20 \mu \mathrm{M} Z \mathrm{Zn}$ and $100 \mu \mathrm{M} \mathrm{Ni}$ (all as sulfate salts), to induce accumulation of both $\mathrm{Zn}$ and Ni. Plants continue to grow well, although some accessions develop mild chlorosis of the leaf blades, but no signs of metal toxicity or severe deficiency are observed when shoots of three plants per accession are mounted for $\mu \mathrm{XRF}$ analysis (Fig. 1).

The possibility of radiation-induced damage in $\mu \mathrm{XRF}$ analysis (especially in fresh hydrated samples) is an important consideration that may limit the information sought from the analysis [23]. The aim of $\mu$ XRF analysis is to examine physiologically as close as possible to the natural state of the plant. 'Damage' can be defined as any change to the specimen that compromises the examination of these processes. We could not discern any physiological changes (such as wilting, discoloration, etc.) consequential to the $\mu \mathrm{XRF}$ analysis. This can be explained because the source produces a flux of $2.2 \times 10^{8}$ photons $\mathrm{s}^{-1}$ in a $25-\mu \mathrm{m}$ beam spot, at a maximum dwell of $100 \mathrm{~ms}$. This results in a deposited radiation dose of just 6.6 Gy [23]. Throughout the study, $\mathrm{Zn}$ and $\mathrm{Ni}$ will be considered, which are the metals provided at elevated concentrations, and which are known to be hyperaccumulated by $N$. caerulescens. In addition, two reference metals, $\mathrm{Ca}$ and $\mathrm{K}$ are considered, which are normally abundant and well spread over the leaf. Total plant metal content is calculated from the $\mu$ XRF scans (Fig. 1 for Zn) and compared to ICP-AES data obtained from material collected after the $\mu$ XRF-scanning (see Additional file 2: Fig S1). These two datasets correlate reasonably well for all metals (Pearson's $r=0.87,0.83,0.78,0.73$ for $\mathrm{Zn}, \mathrm{Ca}$, $\mathrm{K}$, and Ni respectively).

\section{Segmentation quality}

Using traditional image-processing techniques, a segmentation algorithm has been designed for the raw images which is applied to the dataset (Fig. 2). Four classes of plant substructures are discriminated: petiole, leaf margin, leaf vasculature (vein) and leaf interveinal tissue (tissue) (Fig. 3c). The algorithmic segmentation is evaluated using 4000 manually classified pixels. Considerable differences in recall and precision are seen between the classes (Fig. $3 \mathrm{~b}$ ). The petiole can be segmented with a recall of $90 \%$. The recall for leaf margin is $74 \%$, with $16 \%$ of the leaf margin pixels being erroneously predicted as petiole. Confusion also exists between vasculature and interveinal tissue pixels resulting in a recall for the vasculature class of $62 \%$ and for the tissue class of $73 \%$ (Fig. 3b). Precision scores 

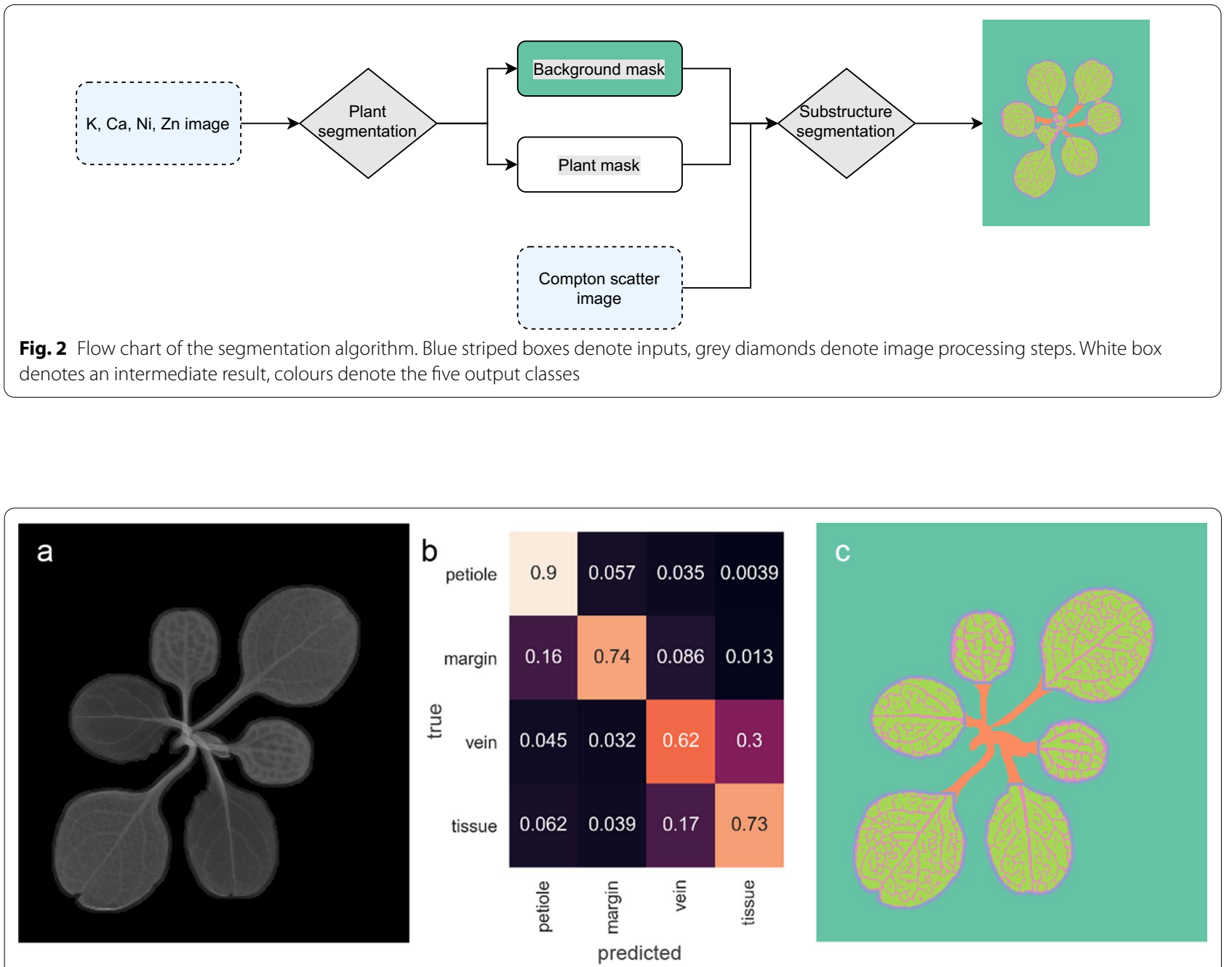

Fig. 3 Comparison of Compton scatter image and pixel-for-pixel classification. a Compton scatter X-ray image of a Noccaea caerulescens plant. b row-normalized confusion matrix showing evaluation of ground-truth. Horizontal axis sums up to 1. c Classification of the major plant structures: petiole (orange), leaf margin (violet), leaf vasculature (vein)(pink) and leaf interveinal tissue (tissue)(green)

for petiole, margin, vasculature, and tissue are, respectively, 0.696, 0.868, 0.721, and 0.633 .

Petioles are misclassified when the petiole crosses or closely borders a leaf. This is often the case for young developing leaves positioned close to the centre of the rosette (Fig. 4a, b). Margin pixels are misclassified as petiole when the leaf extends along the petiole (Fig. 4c, d), or wherever small developing leaves are erroneously classified as petiole. Vasculature and interveinal tissue are mixed up in the vicinity of tertiary vasculature because image resolution is too low to discriminate these very fine structures (Fig. 4e, f, g, h). Finally, the method cannot handle very small plants, which are completely mis-classified as "petiole", but this only applied to three plants in the experiment.
A sensitivity analysis shows effects of segmentation parameter values on the harmonic mean of precision and recall (F1-score). Increased F1-scores in one substructure often coincide with decreased scores in other substructures (Fig. 5). Increasing the kernel size used for the morphological opening causes a larger part of the plant to be classified as petiole (Fig. 5a). The increase in petiole F1-score coincides with decreased F1-scores for all other substructures. Sensitivity of the F1-score is tested for three parameters that influence vein and tissue segmentation; the Laplacian operator kernel size (Fig. 5b) and two binary thresholds that convert the result of the Laplacian operation into vasculature- and intervascular tissue masks (Fig. 5c, d). Increasing the kernel size causes more pixels to 

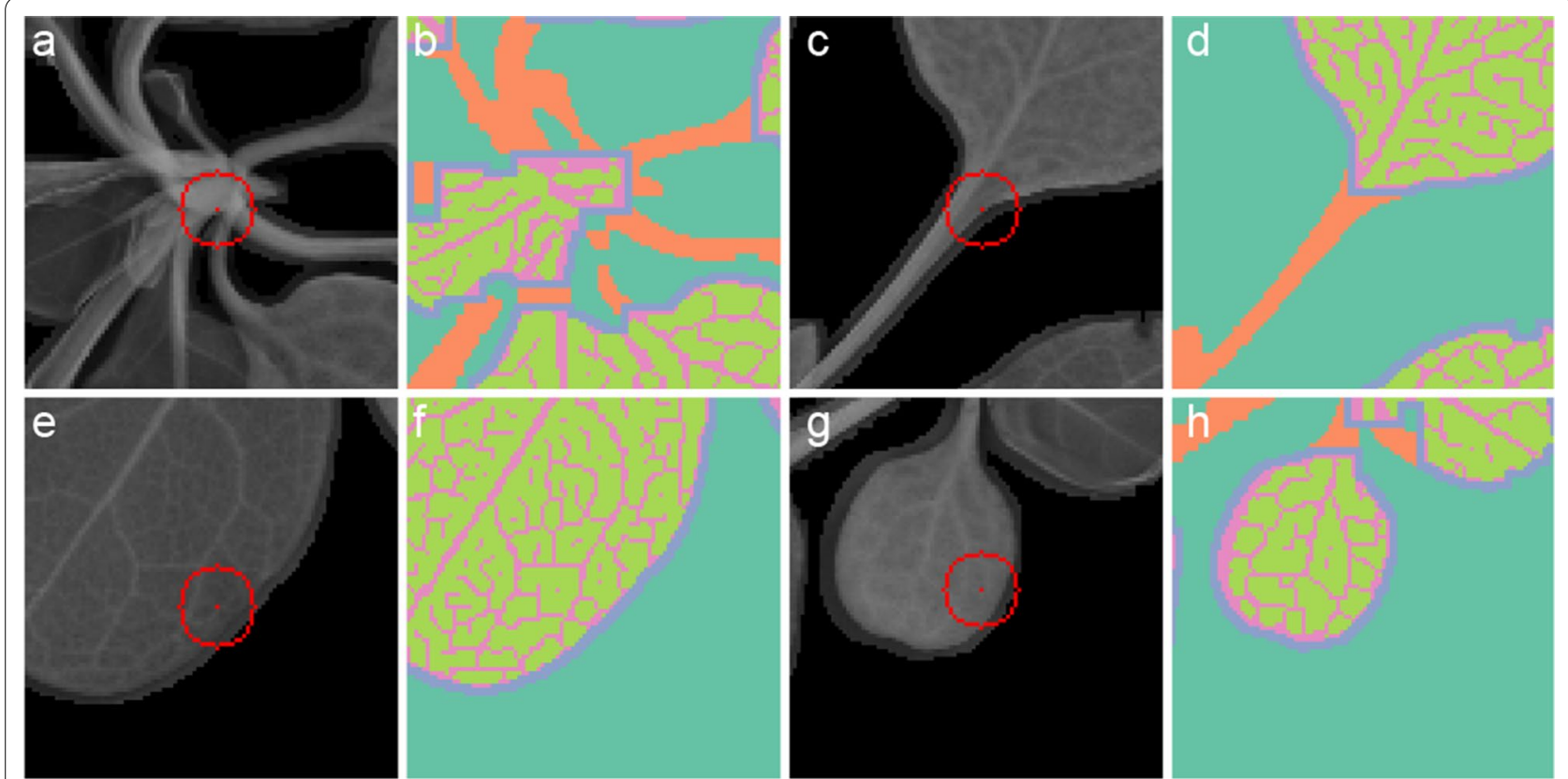

Fig. 4 Examples of misclassified pixels. Compton scatter and segmentation of petiole $(\mathbf{a}, \mathbf{b})$, leaf margin $(\mathbf{c}$, $\mathbf{d})$, leaf vasculature $(\mathbf{e}, \mathbf{f})$, and leaf interveinal tissue $(\mathbf{g}, \mathbf{h})$

be classified as vein and less as tissue (Fig. 5b). This raises the F1-score for both vein as well as tissue. A similar pattern is visible for the threshold on the Laplacian that segments thin vasculature from tissue (Fig. 5c). Hardly any effect on the F1-score is observed when changing the threshold for segmenting thick vasculature (Fig. 5d); increases in recall are set off by decreases in precision and vice versa (see Additional file 2: Fig S2).

\section{Comparison of leaf substructures}

To compare metal accumulation in substructures across all accessions, the metal concentrations are first normalized to the plant mean (Fig. 6). A large range of normalized mean substructure concentrations is visible for the petiole and margin across all metals. Remarkably, while $\mathrm{Zn}$ and $\mathrm{Ni}$ colocalize in most plants, this does not result in equal amounts of under- and overaccumulation of the two metals in any given substructure. The vasculature is the only substructure that consistently accumulates all metals above the plant mean. Other substructures over accumulate some metals but under accumulate others. The differences reported here are only observed when metal concentrations are normalized; the large variation in mean plant metal concentration between the accessions overshadows the differences of within-plant metal distribution (Fig. 6).

\section{Broad-sense heritability determination}

Broad-sense heritability $\left(\mathrm{H}^{2}\right)$ values indicate how much the phenotypic variance of a population can be explained by genetic rather than environmental factors [37]. $\mathrm{H}^{2}$ can be used to relate phenotypic traits to genetic variation and is an important tool for evolutionary biology and plant breeding [37, 38]. The higher the $\mathrm{H}^{2}$, the easier it will be to use the trait values for genetic analysis, as the phenotypic variation effectively reflects genotypic variation. Since we have determined phenotypes for three replicate plants of each genotypically homogeneous accession, we can estimate the non-genotypic (environmental/error) component of the total phenotypic variance, from the variance within genotypes. Next to several metal concentration and distribution traits, we have also measured plant size, which is for many plant species a trait with high heritability. As an example (Fig. 7), the phenotypic variation for plant size is high, when comparing the different accessions, but much smaller between plants of the same accession. Consequently, the broadsense heritability of plant size is high, at $87.8 \%$ (Fig. 7d).

To determine the heritability of metal accumulation in substructures, a metric is sought that holds information on the accumulation in a substructure independent of the substructure's size and mean concentration in the plant. The concentration quotient fulfils these demands. It expresses the mean concentration in the substructure divided by the mean concentration in the plant (Eq. 13). 

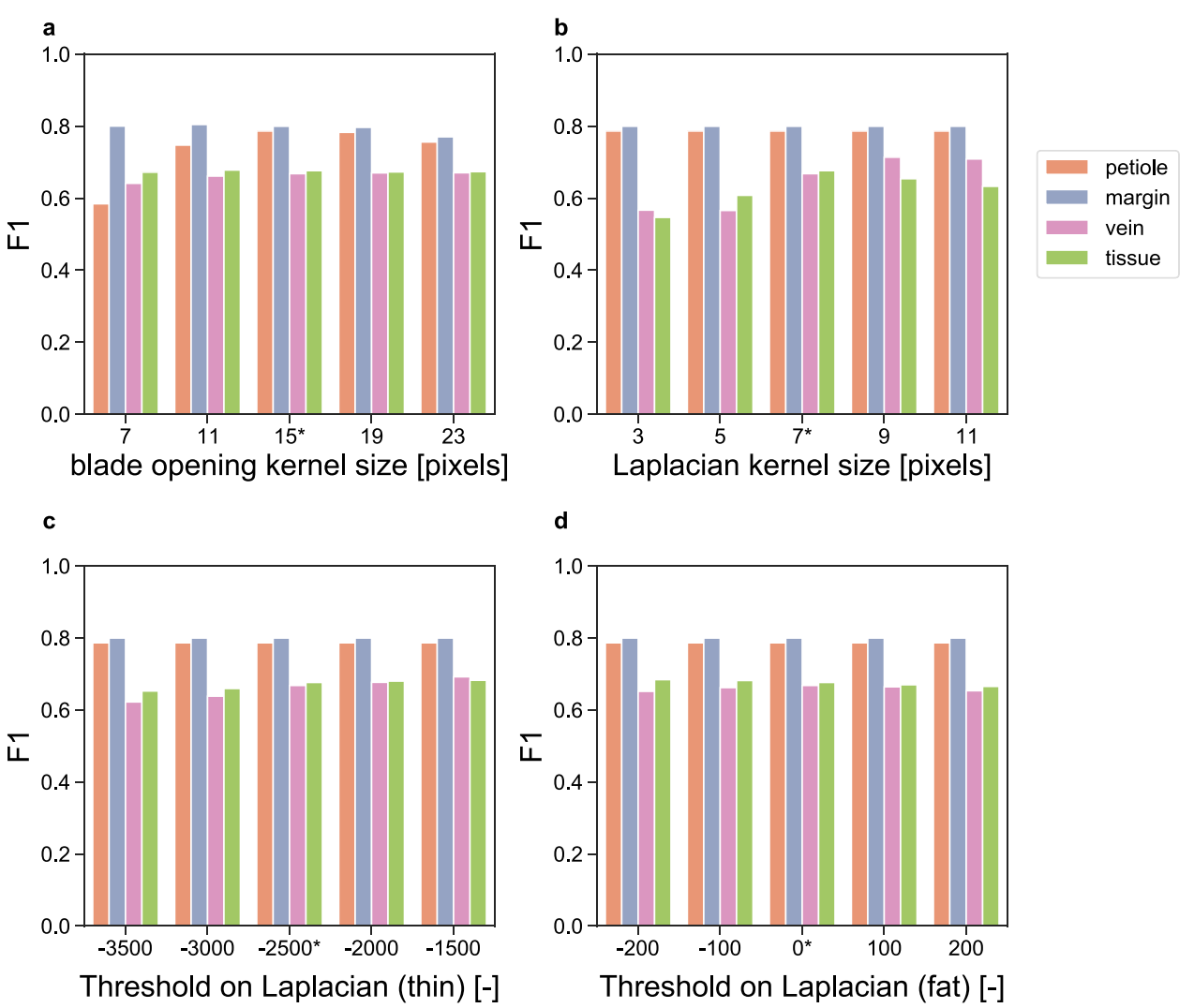

Fig. 5 Sensitivity segmentation quality to four segmentation parameters by F1-score. a Kernel size used for morphological opening operation on binary plant masks to yield blade and petiole separation. b Kernel size of Laplacian operator to detect edges. $\mathbf{c}$ Binary threshold on the calculated Laplacian operator to segment thinnest vasculature. $\mathbf{d}$ Binary threshold on the calculated Laplacian operator to segment wider vasculature. Values on the X-axis with asterisk are used for all analyses. Substructures are indicated in orange (petiole), violet (leaf margin), lilac (leaf vasculature; vein) and green (interveinal tissue; tissue)

Similar to plant size, the $\mathrm{Zn} C Q$ values of the petiole (Fig. 7b) also show low variation within accessions, and high variation between accessions. The same is true for the $\mathrm{Zn} C Q$ values of all other analysed substructures. The plant mean concentration of $\mathrm{Zn}$ results in the highest $\mathrm{H}^{2}$ at $94.7 \%$ (Fig. $7 \mathrm{~d}$ ).

To exclude the possibility that the CQ-metric measures some other heritable trait by proxy, we have examined whether the metal CQs of substructures correlate with plant size, mean metal concentration or the size of the substructure relative to that of the plant. Metal CQs of the petiole, leaf margin and leaf interveinal tissue generally correlate only weakly with plant size and mean $\mathrm{Zn}, \mathrm{Ni}, \mathrm{K}$, and $\mathrm{Ca}$ concentrations (see Additional file 2: Table S1). For $\mathrm{Zn}$ vein $\mathrm{CQ}$ there is some correlation with plant size $(r=0.15)$ and mean zinc concentration $(r=0.41)$. This indicates that plants with higher $\mathrm{Zn}$ concentrations tend to store it increasingly in their vasculature. Also, for the other three metals there is a correlation between metal vein $C Q$ and mean concentration, but the correlation is not always positive (see Additional file 2:
Table S1). Nickel vein CQ correlates positively with mean metal concentration $(r=0.38)$, while $\mathrm{K}$ - and $\mathrm{Ca}-\mathrm{CQ}$ correlate negatively with mean metal concentration (respectively, $r=-0.34$, and $r=-0.55$ ). The latter means that $\mathrm{K}$ and $\mathrm{Ca}$ are not increasingly stored in the vasculature upon increasing metal concentration. All metals in all substructures correlate only weakly with the relative substructure size (see Additional file 2: Table S1).

As expected, there is negative pairwise correlation between the $\mathrm{ZnCQ}$ s of the different substructures. Notably, the vein $\mathrm{ZnCQ}$ correlates to the margin $\mathrm{Zn} C Q$ with $r=-0.50$ and margin $\mathrm{Zn} \mathrm{CQ}$ correlates to petiole $\mathrm{Zn}$ CQ with $r=-0.41$; an increased accumulation in one substructure is paired with a decreased accumulation in one or more other substructures. Similar correlations are found for pairwise substructure CQ correlations for other metals (See Additional file 2: Fig. S3).

As a control for the validity of CQ as a metric for metal accumulation heritability, random substructures are created for every plant. These random substructures consist of five square patches randomly distributed over the 

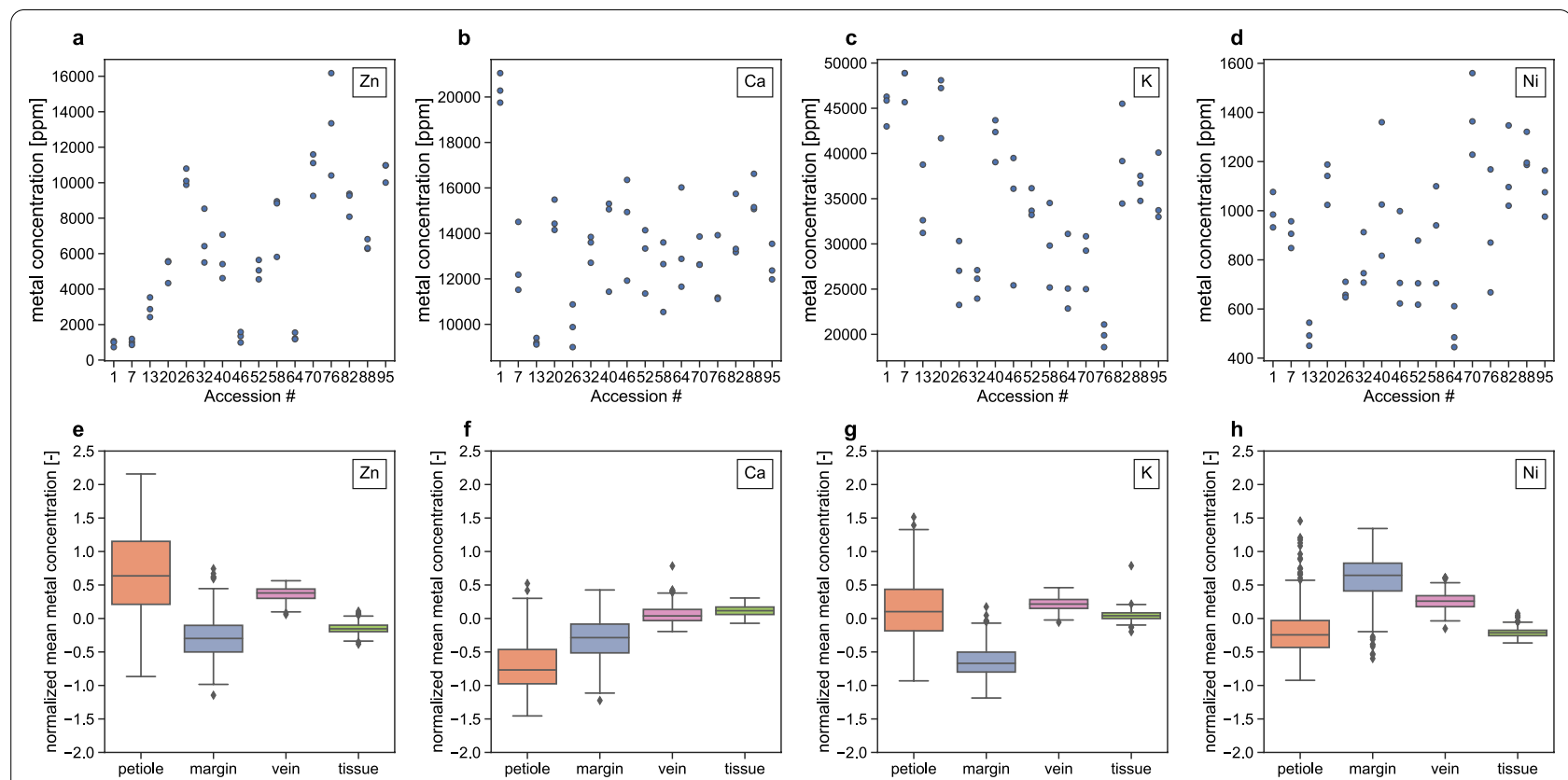

Fig. 6 Distribution of shoot metal concentration for every 6th accession for respectively $\mathrm{Zn}, \mathrm{Ca}, \mathrm{K}$, and $\mathrm{Ni}$ (a-d) as measured by ICP-AES. Comparison of normalized mean metal concentrations per substructure for all $\mathrm{N}$. caerulescens accessions for respectively $\mathrm{Zn}, \mathrm{Ca}, \mathrm{K}, \mathrm{Ni}$, (e-h) derived from $\mu X R F$ image analysis. Mean substructure metal concentrations are Z-score-normalized using the plant mean and standard deviation
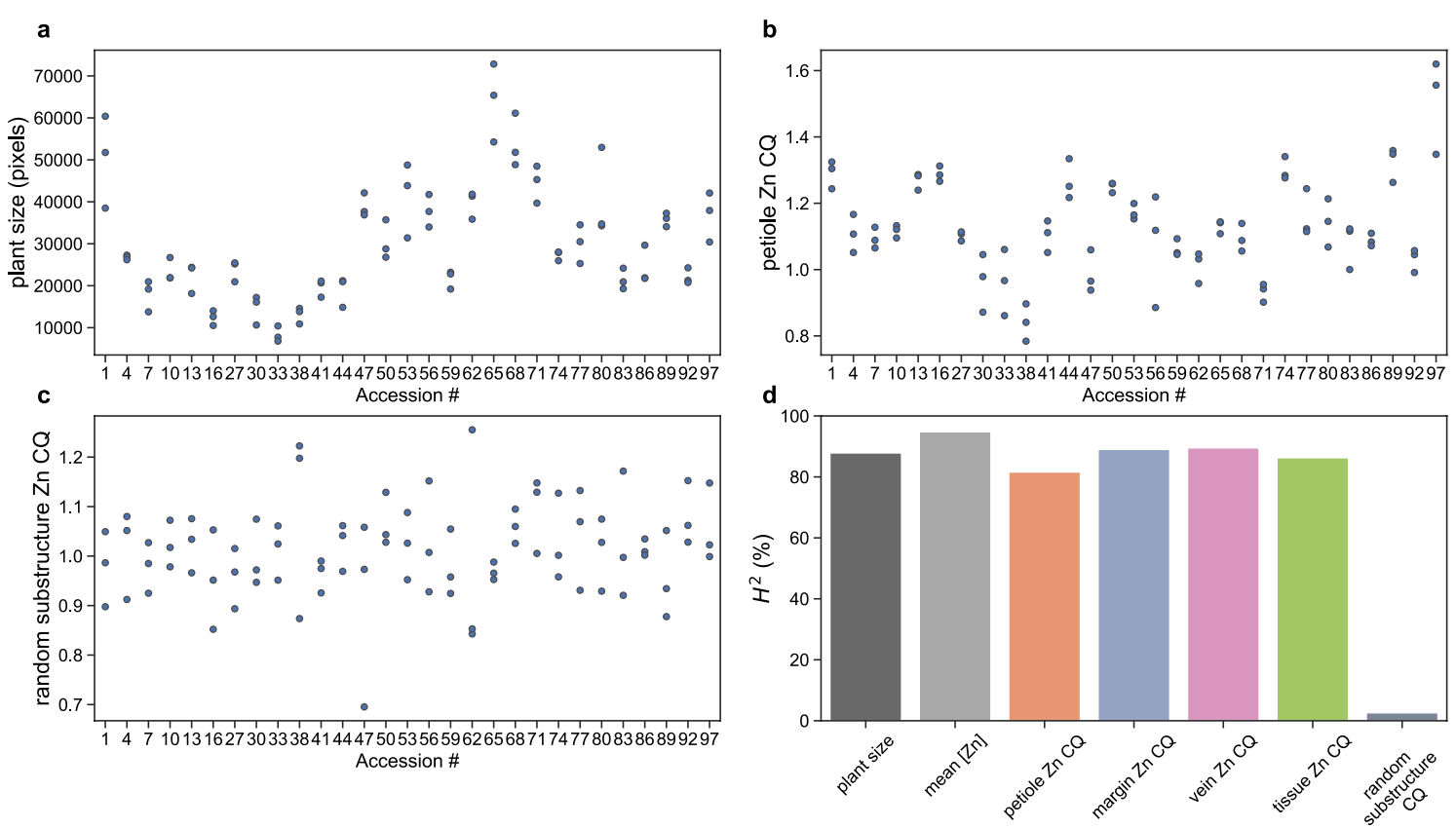

Fig. 7 Genetic variation for traits determined based on the $\mu X R F$ images for three plants per N. caerulescens accession, for a plant size, $\mathbf{b}$ zinc CQ values for the petiole, $\mathbf{c}$ zinc CQ values for a randomly drawn substructure. Every third accession in the dataset was chosen for display. In $\mathbf{d}$, some of the broad-sense heritability $\left(\mathrm{H}^{2}\right)$ scores (in \% of total phenotypic variance) for indicated traits and for the random substructure CQ value are shown 
plant image. The $\mathrm{H}^{2}$ for the random substructures $\mathrm{CQ}$ is very low (Fig. 7c). Such low $\mathrm{H}^{2}$ is indeed expected unless there is an unforeseen problem with the CQ value calculation or the image processing, which is not the case.

Finally, we assessed the robustness of CQ values against classification errors, by introducing 'noise' into the classification algorithm. This is done by assigning a random class to a certain percentage of plant pixels, but this hardly alters the $\mathrm{H}^{2}$ scores even when assigning random classes to $>20 \%$ of the plant's pixels (see Additional file 2: Fig. S4), meaning this image assessment method is robust against segmentation errors.

The $\mathrm{H}^{2}$ of substructure $\mathrm{CQ}$ is very high across all substructures and imaged metals, all above 75\% (Fig. 8). In a way this is remarkable, as a pair-wise correlation between the metals shows that the CQs of substructures are only weakly correlated (See Additional file 2: Fig. S5), not exceeding $r=0.34$. The only exceptions are the correlation between $\mathrm{Ni}$ and $\mathrm{Ca} C \mathrm{CQ}$ for the vasculature $(r=-0.55)$, and of $\mathrm{Zn}$ and Ni CQs $(\mathrm{r} \geq 0.46$ for any

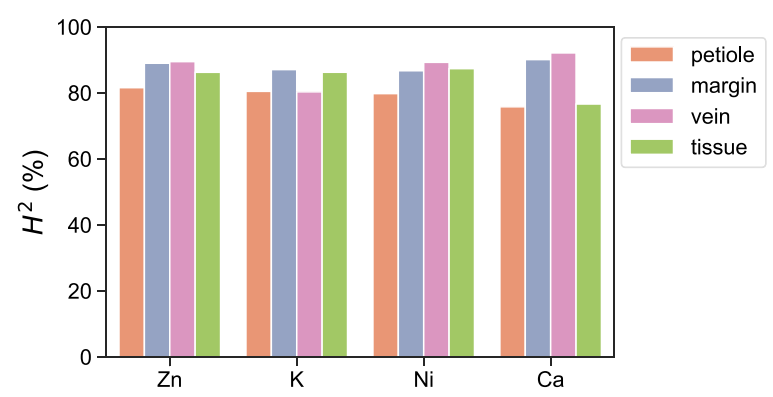

Fig. 8 Broad-sense heritability $\left(H^{2}\right)$ of metal accumulation for each the four substructure CQ values for zinc (Zn), potassium (K), nickel $(\mathrm{Ni})$, and calcium (Ca) for the petiole (orange), leaf margin (violet), leaf vasculature (vein; lilac) and leaf interveinal tissue (tissue; green) substructures substructure). This means that while the $\mathrm{H}^{2}$ of substructure CQs are consistently high across metals, this is not caused by common biological processes, except perhaps for the regulation of $\mathrm{Zn}$ and $\mathrm{Ni}$ homeostasis in leaves.

\section{Heritability of metal colocalization}

While CQ could be used to quantify the spatial localization of metals, it does not quantify the colocalization of metal pairs. The extent of metal colocalization can be investigated by calculating a Pearson's correlation coefficient per plant for the pixel values of every pair of metal images (Fig. 9). A remarkable diversity is observed with metal correlations ranging from weak negative correlations to moderately positive correlations depending on the accession. The exception is the correlation between $\mathrm{Zn}$ and $\mathrm{Ni}$; for all plants there is a weak to strong positive correlation between $\mathrm{Zn}$ and Ni concentrations (Fig. 9a). The extent of colocalization between metal pairs varies between genotypes; plants within accessions display similar correlation coefficients, while correlation coefficient differences between accessions are relatively large. This results in high broad-sense heritability for all analysed metal pairs (Fig. 9b).

\section{Discussion}

\section{Image-segmentation quality}

For most leaf structures, the image segmentation was successful. Only image segmentation of the vasculature may need future improvement. While the segmentation of primary and secondary vasculature was successful, the prediction of tertiary vasculature was very unprecise. The current resolution of the $\mu \mathrm{XRF}$ image is lower than the width of most tertiary vasculature, resulting in the pixels only partially representing the reflectance of the vasculature, with a large influence of the interveinal tissue. This makes it difficult to accurately classify pixels as either
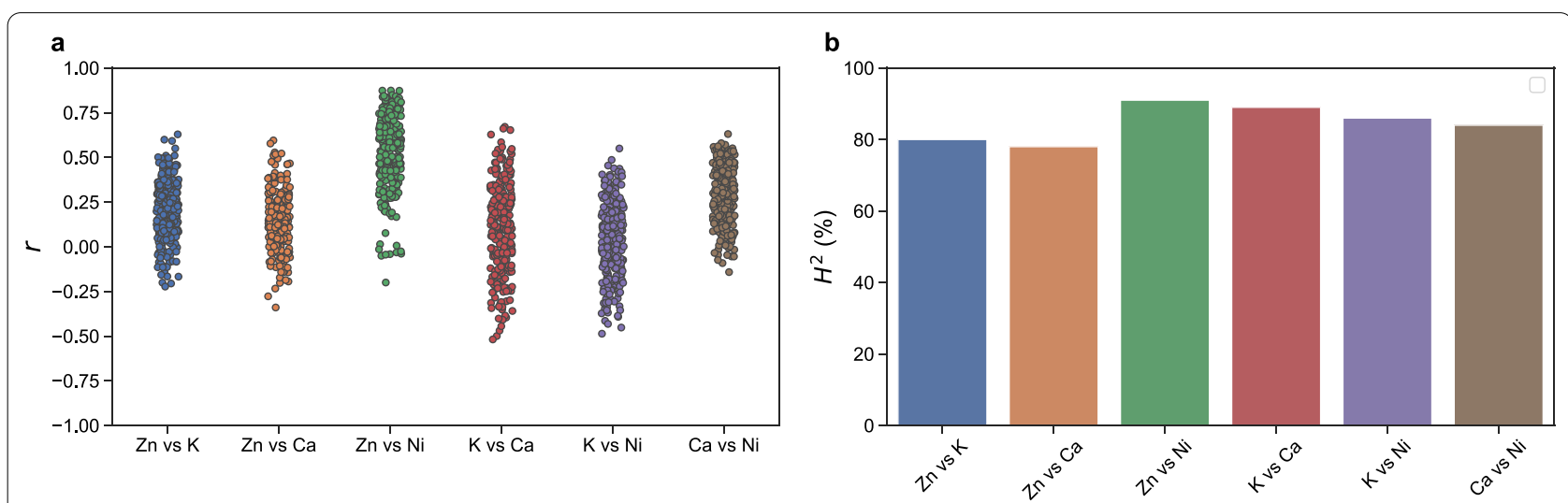

Fig. 9 Colocalization of metals. a Correlation coefficients $(r)$ for correlation of the zinc (Zn), calcium (Ca), potassium (K) and nickel (Ni) pixel-based concentration values per plant. b Broad-sense heritability $\left(\mathrm{H}^{2}\right)$ of the correlation coefficients 
vasculature or interveinal tissue. The reported segmentation accuracy is also influenced by errors in the manual ground-truth labelling. The problem of low resolution of the tertiary vasculature also challenges manual classification. The exact pixel at which the blade-edge starts is somewhat arbitrary, leading to some errors in setting the ground-truth for the margin segmentation. Similarly, the boundary between the substructures petiole and leaf margin is somewhat arbitrary to draw. Furthermore, in many images, a narrow strip of leaf blade can be seen running along the petiole, this cause misclassification of some leaf margin areas as petiole.

While a higher-resolution image could solve some of these problems, adjustment of the segmentation strategy could provide an alternative solution. Instead of classifying all pixels in the image, some regions of high uncertainty could be excluded. In particular, the tertiary vasculature and surrounding areas as well as the region where blade and petiole meet could be excluded. This approach was not used in the current investigation as the CQ-based $\mathrm{H}^{2}$ seemed robust enough against misclassification. Moreover, excluding specific regions could introduce some bias in the concentration quotients.

\section{Image segmentation sensitivity \& generalizability}

As expected, the segmentation method is sensitive to variation of the image processing parameters. While the general strategy of segmenting plant structures based on shape- and pixel intensity-attributes can be translated to other datasets and species, the exact algorithm and parameter values will need to be optimized for new settings. A custom segmentation algorithm would need to be created for every new species. When generalization to many other species is desired, we recommend the introduction of a machine-learning approach. To this end, the image processing strategy described in this article could be used to generate a labelled ground-truth dataset for multiple species. Next, a deep convolutional neural network could be trained to learn generalized substructure segmentation from this data [39]. Alternatively, synthetic data could be created by generating images based on structural plant models [40-42]. However, structural plant models would require reparameterization for individual species as well. This is likely to take an equal or longer time than the image processing strategy described here. It will however result in a significantly larger dataset.

\section{Image segmentation robustness}

In many cases, the accuracy of image segmentation is essential for the reliable extraction of spatial attributes from metallome maps. However, because the calculated CQs are averaged over the plant substructures, the metric turned out to be robust against misclassification of plant pixels; insertion of noise in the segmentation algorithm did not affect CQ heritability when $20 \%$ of pixels were randomly classified. Remarkably, when noise is injected by assigning a random class to $\geq 50 \%$ of the pixels, heritability is still high. This is probably because the majority of the plant surface is taken up by the interveinal tissue. As the majority of pixels in each plant belongs to this interveinal tissue class, when random classes are assigned to a progressive percentage of pixels, the true underlying class becomes progressively dominated by the interveinal tissue class. Therefore, for injection percentages larger than $20 \%$, the substructure CQs increasingly reflect the tissue $\mathrm{CQ}$, which on its own has high $\mathrm{H}^{2}$ (see Additional file 2: Fig. S4).

\section{Heritability of metal accumulation patterns}

Previous work linking phenotype to genotype through heritability has relied much on one-dimensional phenotypic traits such as yield components [43, 44], morphology [45], or photosynthetic efficiency [46, 47] and/ or traits relating to plant geometry $[47,48]$. Here, we translate spatial concentration patterns into a numerical metric to link them to genetic variability. This may allow for the discovery of novel genes and regulatory elements of these complex processes. In addition to the already established link of total metal accumulation to genotype [10], we show here that the spatial accumulation patterns are also heritable. The concentration quotient is a robust metric to determine heritability of metal accumulation patterns. We expect that this metric can be combined with data on single nucleotide polymorphisms between accessions to find novel genes and regulatory processes involved in metal homeostasis. The heritability of metal CQs is remarkably similar across different metals even though CQs for the different metals are only slightly correlated to one another. Some of the similarity in heritability across metals may be explained by the method with which $\mu \mathrm{XRF}$ intensity rasters were converted into concentration rasters; an equal thickness was assumed for the whole plant. If the thickness of the substructures varies individually between accessions, this may have affected the reported concentrations in the substructures. Therefore, some of the CQ heritability may relate to substructure thickness instead of metal accumulation. To counter this, any strong relationship between sample thickness and metal concentration would have shown up as a correlation between the pixel intensities of the different metals. This correlation was not observed. Still, for future investigations we recommend an estimation of the thickness of substructures [49]. No other phenotypic traits were found that explain the consistent patterns of substructure CQ heritability. 


\section{The impact of the plantlet thickness on metal} accumulation analysis through $\mu$ XRF scanning

The thickness of $N$. caerulescens leaves varies, with petioles thicker than the foliar vasculature and the leaf lamina the thinnest. This may affect the calculation of total metal content based on $\mu$ XRF scanning images. When we perform a sensitivity analysis for sample thickness using a portable XRF scanner, it is apparent that sample thickness variations between 200 and $800 \mu \mathrm{m}$ (the thickness range observed for $N$. caerulescens) do not have a major effect on the intensity of the $\mathrm{K}$ and $\mathrm{Ca}$ signals. However, for the heavier $\mathrm{Ni}$ and $\mathrm{Zn}$ elements the difference becomes more pronounced (see Additional file 2: Fig S6). This will enhance any positive correlation of observed $\mathrm{Zn}$ and Ni concentrations but will only have a minor effect on the CQ values for these metals.

\section{Metal accumulation and colocalization patterns}

While the biological interpretation of the images and the heritability analysis is not the focus of this report, and has not been analysed in great detail, it is still interesting to draw a few conclusions. $N$. caerulescens is a metal hyperaccumulator of three, perhaps even four, metals, $\mathrm{Zn}, \mathrm{Ni}$, $\mathrm{Cd}$ and $\mathrm{Pb}$, which in itself is a rare trait. $\mathrm{Zn}$ and $\mathrm{Ni}$ hyperaccumulation is so far only described for the Noccaea genus and the Dichapetalum genus [50]. The few species in which natural $\mathrm{Ni}-\mathrm{Zn}$ hyperaccumulation may occur are therefore likely to be members of the Noccaea genus. However, since high concentrations of both $\mathrm{Ni}$ and $\mathrm{Zn}$ in soil rarely occurs in nature, co-hyperaccumulation of both metals will only accidently occur in natural populations of Noccaea species. For all N. caerulescens plants we examined, wide ranges of colocalization were observed for the metal pairs, from no obvious colocalization to strong positive or negative colocalization. The only metal pair that showed consistent positive correlation in spatial concentrations was that of $\mathrm{Zn}$ and $\mathrm{Ni}$. As noted above, this correlation may have been emphasized by local differences in leaf thickness that influence especially the $\mathrm{Zn}$ and $\mathrm{Ni}$ measurements but not those of $\mathrm{Ca}$ and $\mathrm{K}$.

The positive colocalization we find appears to contrast with previous observations for $N$. caerulescens [16] and our earlier observations in the closely related Noccaea tymphaea [19] in which different localization patterns for $\mathrm{Zn}$ and $\mathrm{Ni}$ were found. One obvious difference in methodology between these reports and our work is that we exposed plants to both elevated $\mathrm{Zn}$ and $\mathrm{Ni}$ supply, in a 1:5 concentration ratio, to ensure accumulation of both metals. The work on N. tymphaea was performed on wild-collected plants and the previous work on $N$. caerulescens was performed on plants supplied with high $\mathrm{Zn}$ or with $\mathrm{Ni}$ supply, but not combined in one treatment. The extent of colocalization in $N$. caerulescens we studied, seems influenced by the genotype of the plant. In our analysis, we find accumulation of metals to associate largely within the vasculature, which is in line with previous findings for $N$. caerulescens in which $\mathrm{Zn}$ was localized using transverse leaf sections [18]. In the other reports on $N$. tymphaea and $N$. caerulescens, the highest $\mathrm{Zn}$ concentrations are found in the tissues surrounding the vasculature $[16,19]$, so slightly out of the vasculature. The aforementioned investigations consider only one or a few accessions. Since metal accumulation patterns are shown to be highly heritable, considering one accession will not be sufficient to make general claims about accumulation patterns on the species level.

\section{Conclusions}

A general strategy for plant substructure segmentation of $\mu \mathrm{XRF}$ scans is proposed for plants similar to $N$. caerulescens in plant architecture, and a metric is developed to link phenotypic variance in the spatial distribution of the plant metallome to genetic variance. Spatial metal-accumulation patterns, as measured by $C Q$, are highly heritable in $N$. caerulescens for all metals and all segmented substructures. While image segmentation quality can benefit from higher resolution images, the segmentation quality was sufficient to extract highly heritable phenotypic traits on metal accumulation. Segmentation quality was highest for petiole and margin, and lowest for vasculature and leaf tissue. The quality depends on the image-processing parameters, which were optimized for the given dataset. The heritability scores for the various tested phenotypic traits were not significantly influenced by the segmentation quality when noise was injected. This indicates that the CQ-metric is robust to, at least some, segmentation error. The strategy employed in this study can be used to quantify elemental distributions patterns obtained from synchrotron or laboratory $\mu \mathrm{XRF}$ datasets of (hyperaccumulator) plants to assist in the comparative analysis of differential accessions, mutants or dose treatments, and thus be a valuable tool for the discovery of new genes that regulate metal homeostasis.

\section{Methods \\ Plant material and cultivation}

A diversity panel of $96 N$. caerulescens accessions is used (Additional file 1), which have all been propagated for at least three generations by single-seed descent upon self-pollination to create phenotypically homogeneous lines. Before germination, surface-sterilized seeds are sown on 0.6-ml PCR-tubes of which the bottom is cut off and which are filled with $0.3 \%$ gelling agent (Gelzan, Sigma-Aldrich) (made with $0.5 \times$ strength Hoagland's nutrient solution). Seeds are stratified for six days at $3{ }^{\circ} \mathrm{C}$, and a drop of $10 \mu \mathrm{M}$ gibberellic acid (GA4+7; Duchefa) 
is applied on top to break any seed dormancy. After germination at $26{ }^{\circ} \mathrm{C}$, tubes with germinated seeds are transferred to the hydroponics culture after three days, when the fully expanded cotyledons have emerged. The hydroponic system is set up in a temperature-controlled growth chamber. Four separate rectangular containers $(11 \mathrm{~cm}$ height $\times 30 \mathrm{~cm}$ width $\times 40 \mathrm{~cm}$ length; $11 \mathrm{~L}$ each) are filled with a modified $0.5 \times$ strength Hoagland's nutrient solution: $3 \mathrm{mM} \mathrm{KNO}, 2 \mathrm{mM} \mathrm{Ca}\left(\mathrm{NO}_{3}\right)_{2} \cdot 4 \mathrm{H}_{2} \mathrm{O}$, $1 \mathrm{mM} \mathrm{NH} \mathrm{H}_{2} \mathrm{PO}_{4}, 0.5 \mathrm{mM} \mathrm{MgSO} \cdot 7 \mathrm{H}_{2} \mathrm{O}, 1 \mu \mathrm{M} \mathrm{KCl}$, $25 \mu \mathrm{M} \mathrm{H} \mathrm{H}_{3} \mathrm{BO}_{3}, 2 \mu \mathrm{M} \mathrm{MnSO}_{4} \cdot 4 \mathrm{H}_{2} \mathrm{O}, 2 \mu \mathrm{M} \mathrm{ZnSO} \cdot 7$ $\mathrm{H}_{2} \mathrm{O}, 0.1 \mu \mathrm{M} \mathrm{CuSO}_{4} \cdot 5 \mathrm{H}_{2} \mathrm{O}, 0.1 \mu \mathrm{M}$ as $\mathrm{Na}_{2} \mathrm{MoO}_{4} \cdot 2 \mathrm{H}_{2} \mathrm{O}$ and $20 \mu \mathrm{M}$ Fe-HBED. The solution is set to pH 5.5 with $\mathrm{KOH}$ and buffered using $2 \mathrm{mM}$ MES (2-( $N$-morpholino) ethane sulfonic acid). The solution is kept constantly aerated using an air stone at the bottom of each container. In each container, 35 plants are grown in open $0.6-\mathrm{mL}$ Gelzan-filled bottomless PCR tubes inserted into $3 \mathrm{~cm}$ round plastic baskets with a foam disk to allow the roots to be immersed in the nutrient solution. After one week, the nutrient solution is replaced with a fresh solution, containing $20 \mu \mathrm{M} \mathrm{ZnSO}_{4}$ and $100 \mu \mathrm{M} \mathrm{NiSO}_{4}$ to induce accumulation of both $\mathrm{Zn}$ and $\mathrm{Ni}$ [10]. To calculate free ionic activity of $\mathrm{Zn}$ and $\mathrm{Ni}$ a simulation has been performed using the software GEOCHEM-EZ, with $90.2 \%$ of $\mathrm{Zn}$ present as the free ion, and $92.2 \%$ of $\mathrm{Ni}$ present as the free ion, in both cases the remainder is complexed with $\mathrm{NO}_{3}, \mathrm{SO}_{4}$ and $\mathrm{PO}_{4}$, while $100 \%$ of $\mathrm{Fe}^{3+}$ is complexed with HBED. The nutrient solutions are changed completely after one week, at which interval the $\mathrm{pH}$ has not changed substantially $(<0.2 \mathrm{pH}$ change). Plants are grown for 20 days in hydroponics with a 12-12 h light-dark photoperiod, under high intensity full spectrum Valoya B200 LED lights (Valoya Oy, Helsinki Finland), with a photosynthetic photon flux density at of $350 \mu \mathrm{mol} \mathrm{m} \mathrm{m}^{-1}$ (measured with an Apogee MQ-500 instrument) at $26 / 20{ }^{\circ} \mathrm{C}$ day/night temperatures.

\section{Elemental mapping using $\mu \mathrm{XRF}$}

Before being destroyed by acid digestion, freshly hydrated, plantlets of which the roots were cut off, were mounted and scanned using a modified ATLAS $\mathrm{X}$ instrument (IXRF Systems) at the Centre for Microscopy and Microanalysis, The University of Queensland, Australia. On the $\mu \mathrm{XRF}$ motion stage $(300 \times 300 \mathrm{~mm})$, the whole plantlets were mounted, and to retain their position, shape, and moisture content during the measurement, the plantlets were sandwiched between a $100-\mu \mathrm{m}$ thick cellulose acetate sheet (below) and a sheet of $6-\mu \mathrm{m}$ thick Ultralene thin film (top). Prior to the mounting of the plantlets the main root was cut off and thereafter the whole plantlet was tightly sealed in the mounting with thin film. There was no visible leakage from the cut surface. The $\mu \mathrm{XRF}$ system is equipped with two $50-\mathrm{W}$ X-ray sources fitted with polycapillary focussing optics: XOS microfocus Motarget tube producing $17.4 \mathrm{keV} \mathrm{X}$-rays (flux of $2.2 \times 10^{8}$ $\mathrm{ph} \mathrm{s}^{-1}$ ) focussing to $25 \mu \mathrm{m} \mathrm{FWM} \mathrm{and} \mathrm{a} \mathrm{Rh-target} \mathrm{tube}$ producing $20.2 \mathrm{keV}$ (flux of $1.0 \times 10^{7} \mathrm{ph} \mathrm{s}^{-1}$ ) focussing to $5 \mu \mathrm{m}$ FWM. It has two KETEK H150 silicon drift detectors of $150 \mathrm{~mm}^{2}$ coupled to a XIA Mercury $\mathrm{X} 4$ signal-processing unit. Typical energy resolution is $<145 \mathrm{eV}$ with a maximum input count rate of $2 \mathrm{M}$ counts per second. During measurements of all plantlets, all parameter settings and environments were kept constant; temperature at $\sim 20{ }^{\circ} \mathrm{C}$, using the Mo $25 \mu \mathrm{m}$ $\mathrm{X}$-ray source at a $50 \mathrm{kV}, 1000 \mu \mathrm{A}$, a rise time of $0.25 \mu \mathrm{s}$ and a per-pixel dwell of $100 \mathrm{~ms}$. The XRF spectra on the UQ $\mu \mathrm{XRF}$ facility were acquired in mapping mode using the instrument control package (Iridium, IXRF Systems) from the sum of counts at the position of the principal K-line fluorescence peak for each element. These were each exported into ImageJ as greyscale 8-bit TIFF files. The sum of counts images for $\mathrm{Zn}, \mathrm{K}, \mathrm{Ca}$, and $\mathrm{Ni}$ as well as the Compton scatter image were used here.

\section{Chemical analysis of plant samples}

At the end of the cultivation period, the plants were harvested and divided into shoots and roots. While the shoots were mounted for $\mu$ XRF scanning (see above), the root samples were rinsed with de-ionised water and dried at $60{ }^{\circ} \mathrm{C}$ for $72 \mathrm{~h}$ in a dehydrating oven. After scanning, also the shoot samples were collected from the cellulose acetate sheet and oven dried. Each sample was then weighed $(\sim 50 \mathrm{mg})$ and digested using $1 \mathrm{~mL}$ $\mathrm{HNO}_{3}(70 \%)$ in a hot block (ThermoFisher Digital Dry Bath) with a 1-h programme at $70{ }^{\circ} \mathrm{C}$ and a further 1 -h at $125{ }^{\circ} \mathrm{C}$, and then diluted to $10 \mathrm{~mL}$ with ultrapure water (Millipore $18.2 \mathrm{M} \Omega \cdot \mathrm{cm}$ at $25^{\circ} \mathrm{C}$ ) for subsequent analysis. Aliquots were analysed by Inductively Coupled Plasma Atomic Emission Spectroscopy (ICP-AES, Thermo Scientific iCAP 7400) for the macro-elements $\mathrm{Na}, \mathrm{Mg}, \mathrm{Al}, \mathrm{P}, \mathrm{S}, \mathrm{K}$ and $\mathrm{Ca}$ and the trace elements $\mathrm{Mn}$, $\mathrm{Fe}, \mathrm{Cu}, \mathrm{Ni}$ and $\mathrm{Zn}$ in radial and axial modes depending on the element and expected analyte concentration. All elements were calibrated with a four-point curve covering analyte ranges in the samples. In-line internal addition standardization with yttrium was used to compensate for matrix-based interferences. Quality controls included matrix blanks, certified reference material (Sigma-Aldrich Periodic Table Mix 1 for ICP TraceCERT ${ }^{\circledR}, 33$ elements, $10 \mathrm{mg} \mathrm{L}^{-1}$ in $\mathrm{HNO}_{3}$ ), and Standard Reference Material (NIST Apple 1515 digested with $\mathrm{HNO}_{3}$ ). 


\section{Segmentation of plant substructures}

Substructure classes were assigned to every pixel in the $\mu \mathrm{XRF}$ scans. One pixel can belong to one of the following five classes: background, petiole, leaf margin (margin), vasculature (vein) or leaf interveinal tissue (tissue). Several traditional image processing techniques were used in sequence to segment the substructures (Fig. 2).

To create the plant foreground mask, the $\mathrm{K}, \mathrm{Ca}, \mathrm{Ni}$ and $\mathrm{Zn}$ grayscale images were binarized using the Otsu thresholding method, which finds the intensity threshold that separates the pixel intensities in two classes based on a minimization of the intra-class intensity variance [51]. This results in four binary masks for each metal type; $M_{\mathrm{K}}$, $M_{\mathrm{Ca}}, M_{\mathrm{Ni}}$, and $M_{\mathrm{Zn}}$. The union of these masks resulted in the plant-foreground mask:

$$
M_{\text {plant }}=M_{\mathrm{K}} \cup M_{\mathrm{Ca}} \cup M_{\mathrm{Ni}} \cup M_{\mathrm{Zn}}
$$

Using morphological image processing [52], the foreground mask could be divided into a blade and a petiole based on the feature that petioles are less wide than blades. An opening operation with a structuring element of size $15 \times 15$ was applied in a single iteration to remove the petiole and yield the blade mask.

$$
M_{\text {blade }}=\operatorname{opening}\left(M_{\text {plant }}, 15 \times 15\right)
$$

Subtracting the blade mask from the plant mask provided the petiole mask. To remove small artefacts from the petiole mask, a connected-component analysis was done and all connected components with an area smaller than $0.001 \%$ of the image area were discarded:

$$
M_{\text {petiole }}=\operatorname{coco}\left(M_{\text {plant }}-M_{\text {blade }}, 0.001 \%\right)
$$

A mask of the leaf margin with a width of three pixels (corresponding to $\sim 100 \mu \mathrm{m}$ ) is obtained by taking the internal gradient, which is the difference between the blade mask and the erosion of the blade mask with a structuring element of size $3 \times 3$ :

$$
M_{\text {margin }}=M_{\text {blade }}-M_{\text {blade }} \ominus b,
$$

where $\ominus$ is erosion and $b$ is the $5 \times 5$ structuring element.

The vein mask was created based on the Compton scatter image, $I_{\text {Compton, which shows the vasculature }}$ with higher intensities compared to the leaf tissue. A Laplacian operator with a kernel size of $7 \times 7$ was used to calculate the second-order derivative of the Compton scatter image in order to detect. The Laplacian highlights regions in the image with rapid intensity change, thus highlighting the vein structure. The result of the Laplacian operation was used in two ways. The thicker primary and secondary vasculature were segmented by thresholding the Laplacian image $M_{\text {vein1 }}$, and the thin tertiary vasculature was located by thresholding the Laplacian image for values below 0 followed by a skeletonization to reduce the thickness of the tertiary vasculature $M_{\text {vein2. }}$. The combined vein mask was obtained from $M_{\mathrm{vein} 1} M_{\mathrm{vein} 2}$ and an intersection to exclude detections on the leaf margin:

$$
\begin{aligned}
& M_{\text {vein1 }}=\operatorname{Laplacian}\left(I_{\text {Compton }}\right)<-2500 \\
& M_{\text {vein2 }}=\operatorname{skeleton}\left(\text { Laplacian }\left(I_{\text {Compton }}\right)<0\right) \\
& M_{\text {vein }}=\left(M_{\text {vein } 1} \cup M_{\text {vein2 }}\right) \cap\left(M_{\text {blade }}-M_{\text {margin }}\right)
\end{aligned}
$$

Finally, the leaf-tissue mask was obtained by taking the difference between the blade mask, the margin mask, and the vein mask.

$$
M_{\text {tissue }}=M_{\text {blade }}-M_{\text {margin }}-M_{\text {vein }}
$$

With the four masks, $M_{\text {blade }}, M_{\text {margin }}, M_{\text {vein }}$, and $M_{\text {tissue, }}$ every pixel in the image is classified in one of the four substructure classes. All image processing steps were carried out using the NumPy (1.19.2) and OpenCVPython (4.2.0.34) packages for Python.

\section{Evaluation of segmentation}

To determine the segmentation quality, for each of the petiole, margin, vein, and tissue substructure classes, 1000 predicted pixels were randomly selected and displayed to a researcher unaware of their predicted class. These pixels were then manually classified as belonging to one of the four classes to obtain a ground-truth classification and to calculate the precision, recall and F1-scores per class: A sensitivity analysis of the F1-score was run on four parameters of the segmentation algorithm.

$$
\begin{aligned}
& \operatorname{Precision}_{i}=\frac{M_{i i}}{\sum_{j} M_{j i}} \\
& \operatorname{Recall}_{i}=\frac{M_{i i}}{\sum_{j} M_{i j}} \\
& \mathrm{~F}_{i}=2 * \frac{\operatorname{Precision}_{i} * \operatorname{Recall}_{i}}{\operatorname{Precision}_{i}+\operatorname{Recall}_{i}}
\end{aligned}
$$

where $M$ is the confusion matrix that holds the groundtruth classes in the rows and the predicted classes in the columns. $M_{r c}$ indicates the value in the confusion matrix on row $r$ and column $c$, which indicates how often a true class $r$ was predicted as class $c$.

A sensitivity analysis of the F1-score was run on four parameters of the segmentation algorithm. Parameter values were incremented from two steps below to two steps above the chosen parameter values. The structuring element used for the opening operation that yielded 
the blade mask $M_{\text {blade }}$ was varied from $7 \times 7$ to $23 \times 23$. The Laplacian operator kernel was varied from $3 \times 3$ to $11 \times 11$. The threshold on Laplacian $\left(I_{\text {Compton }}\right)$ that yielded $M_{\text {vein1 }}$ (Eq. 5) was varied from -3500 to -1500 . The threshold on Laplacian $\left(I_{\text {Compton }}\right)$ that yielded $M_{\text {vein2 }}$ (Eq. 6) was varied from -200 to 200.

\section{Random substructures}

In addition to the segmented substructures, "random substructures" were generated. A random mask was created to compare heritability of phenotypical traits for real substructures (petiole, margin, tissue, veins) to a random non-existing substructure. The heritability in these nonexisting substructures was expected to be low and served as a negative control of our heritability calculations.

For every plant, a random mask was generated consisting of 5 squares of $30 \times 30$ pixels at a random location on the plant surface. Where these squares overlapped with the background, they were cropped to be fully contained within the boundaries of the plant mask.

$$
M_{\text {random }}=\text { random_squares }\left(M_{\text {plant }}\right) \cap M_{\text {plant }}
$$

\section{Concentration Quotient}

The images of metal concentrations can be translated into a numerical trait by analysing the accumulation in plant substructures relative to the whole plant. To this end we introduce the "concentration quotient" (CQ) as the mean concentration in a plant substructure (e.g., the petiole) divided by the mean concentration in the whole plant:

$$
\mathrm{CQ}=\frac{\frac{1}{N_{s}} \sum_{(x, y) \in A_{s}}(P(x, y))}{\frac{1}{N_{p}} \sum_{(x, y) \in A_{p}}(P(x, y))}[-]
$$

where $N_{p}$ and $N_{s}$ are the number of pixels belonging to respectively the plant and the substructure, $A_{p}$ and $A_{s}$ are the set of pixels belonging respectively to the plant and to a substructure, and $P(x, y)$ is the $\mu \mathrm{XRF}$ derived concentration of a pixel at location $(x, y)$. If $C Q=1$, the mean concentration within a substructure is equal to that of the plant. CQ $>1$ shows relative higher concentration within the substructure, while $C Q<1$ shows relative lower concentration within a substructure. CQ allows for an estimation of the heritability of spatial metal distribution.

\section{Heritability and other statistics}

The contribution of genotype to the observed phenotypes was calculated by estimating the broad-sense heritability $\left(\mathrm{H}^{2}\right.$, also called repeatability [53]):

$$
H^{2}=\frac{\operatorname{Var}(G)}{\operatorname{Var}(T)}
$$

$\operatorname{Var}(G)$ is the variance of the genotype and $\operatorname{Var}(T)$ is the total variance. The $\mathrm{H}^{2}$ scores were calculated for the CQs of $\mathrm{Zn}, \mathrm{K}, \mathrm{Ca}$, and $\mathrm{Ni}$ for the petiole, leaf margin, leaf interveinal tissue and leaf vasculature substructures (in total 16 traits). For comparison, $\mathrm{H}^{2}$ was also calculated for plant size and the mean plant concentration of the four metals. Variance components were estimated using mixed models of the following form:

$$
P=G+\varepsilon
$$

where both $\mathrm{G}$ (genotype) and $\varepsilon$ (error) are random terms in the mixed model. A mixed model is fit so that the $n$ accessions are represented by a vector $\beta$ of size $n$ that estimates the observed numerical phenotypes of the replicates as closely as possible. The difference between this estimation and the actual observed numerical phenotype results in the error term $\varepsilon$. $\operatorname{Var}(G)$ is the variance of $\beta$. $\operatorname{Var}(T)$ is the sum of $\operatorname{Var}(e)$ and $\operatorname{Var}(G)$.

$$
\operatorname{Var}(T)=\operatorname{Var}(G)+\operatorname{Var}(\varepsilon)
$$

All models were checked for assumptions of normality and equal variance. Assumptions hold for all models except those in which the CQ of a random substructure was used as phenotype (see "random substructures" below). In these cases, there is some correlation between fitted model values and model residuals. The variance components were estimated by the VarCorr function from the lme4 package in $\mathrm{R}$ statistical software. Total variance was calculated as the sum of the Genotype and $\varepsilon$ variance.

All reported correlation coefficients $(r)$ were calculated using Pearson's correlation coefficient. Code is available at https://github.com/LucasYEAST/noccaea.

\section{Sensitivity analysis on the effect of the sample thickness}

The thickness of the imaged rosette leaves is not constant. To assess the impact of sample thickness on the accuracy of metal concentration calculations, seventeen leaves of $\mathrm{N}$. caerulescens were used to cut 6-mm diameter discs from, that were dried in the oven for $48 \mathrm{~h}$ at $60{ }^{\circ} \mathrm{C}$. The disc leaves were measured using a portable XRF instrument (Thermo Fisher Scientific Niton XL3t 950 GOLDD+) on top of a sheet of paper, a 2-mm thick titanium $(99.995 \%$ pure) plate, and a $2-\mathrm{mm}$ thick molybdenum (99.995\% pure) plate [49], followed by acid digestion for ICP-AES analysis. The spectra of the disc leaves were processed using the GeoPIXE software (http://nmp.csiro. $\mathrm{au} /$ GeoPIXE.html), and the modelled thickness parameter was adjusted to vary from $200 \mu \mathrm{m}$ to $800 \mu \mathrm{m}$ with an 
increment of $100 \mu \mathrm{m}$. The concentrations determined by ICP-AES analysis were used as a comparison with concentrations calculated based on GeoPIXE analysis.

\section{Abbreviations}

MXRF: Micro-X-ray fluorescence microscopy; CQ: Concentration quotient; $\mathrm{H}^{2}$ : Broad-sense heritability; XRF: X-ray fluorescence microscopy; margin: Leaf margin; vein: Leaf vasculature; tissue: Leaf interveinal tissue.

\section{Supplementary Information}

The online version contains supplementary material available at https://doi. org/10.1186/s13007-021-00784-9.

\section{Additional file 1. List of Noccaea caerulescens accessions used.}

Additional file 2: Figure S1. Scatter plots showing $\mu$ XRF- versus ICP-AES determined total metal content data per plant. Figure S2. Sensitivity analysis on recall and precision. a), e) kernel size used for morphological opening operation on binary plant masks to yield blade and petiole separation. b), f) kernel size of Laplacian operator to detect edges. c), g) Binary threshold on the calculated Laplacian to segment thinnest vasculature d), h) Binary threshold on the calculated Laplacian to segment wider vasculature. Values on the X-axis with asterisk are used for all analyses. Figure S3. Correlation coefficients for pairwise correlations of the four substructure CQ for the four metals investigated. Figure S4. Robustness of CQ to incorporation of noise. $a, b, c, d, e, f$ show the distribution of actual pixel classes under the noise-injected masks. For noise injection > 20\% all classes in the noise masked have a majority of pixels that actually belong to the "tissue"-class. g) Broad-sense heritability $\left(\mathrm{H}^{2}\right)$ of zinc $\mathrm{CQ}$ for the four substructures where the classification of substructures has been injected with increasing amounts of class noise. Percentages denote the fraction of pixels in the plant that has been assigned a random substructure class. Injection of noise does not decrease $\mathrm{H}^{2}$. Figure S5. Correlation coefficients for correlations between the CQs of metal-pairs for all substructures. Figure S6. The ratios of metal concentrations as calculated based on GeoPIXE analysis of portable XRF data, compared to the concentrations determined by ICP-AES, as a function of the sample thickness parameter set in the GeoPIXE quantification. Ni concentrations are below the detection limit of the portable XRF instrument and are not included. Table S1. Correlation of substructure CQ with three other plant traits.

\section{Acknowledgements}

The $\mu$ XRF analysis was undertaken at the Centre for Microscopy and Microanalysis (CMM) at the University of Queensland, Australia. We thank Chris Ryan (Commonwealth Scientific and Industrial Research Organisation) and Frank Swehosky and Mandi Hellested (IXRF Systems) for technical support with the $\mu$ XRF analysis and Tom Theeuwen (Wageningen University) for advice on calculating the $\mathrm{H}^{2}$. We acknowledge the support of the AMMRF at the Center for Microscopy and Microanalysis at the University of Queensland.

\section{Authors' contributions}

MGMA and AvdE designed and conducted the $\mathrm{XRFF}$ experiment, with the help of JY to select the accessions and produce the seeds, of ACR to grow part of the plants and prepare plants for scanning, and ICP-AES, of LWC to extract and process the $\mu$ XRF scans and of IP to perform the ICP-AES and sample thickness analysis. LvdZ and GK designed the image analysis experiment, LvdZ performed the image data processing and analysis, and heritability calculations. LvdZ wrote the first draft of the manuscript, all authors commented and discussed this and contributed to writing the final manuscript. All authors read and approved the final manuscript.

\section{Funding}

$J Y$ is supported by a PhD research grant from the Royal Thai Government.

\section{Availability of data and materials}

The code created during the current study is available in the Noccaea repository, https://github.com/LucasYEAST/noccaea. The datasets used and/ or analysed during the current study are available from the corresponding author on reasonable request.

\section{Declarations}

Ethics approval and consent to participate Not applicable.

\section{Consent for publication}

Not applicable.

\section{Competing interests}

The authors declare they have no competing interests.

\section{Author details}

${ }^{1}$ Farm Technology, Department of Plant Sciences, Wageningen University and Research, Wageningen, The Netherlands. ${ }^{2}$ Laboratory of Genetics, Department of Plant Sciences, Wageningen University and Research, Wageningen, The Netherlands. ${ }^{3}$ Centre for Mined Land Rehabilitation, Sustainable Minerals Institute, The University of Queensland, Brisbane, Australia. ${ }^{4}$ Centre for Microscopy and Microanalysis, The University of Queensland, Brisbane, Australia.

Received: 7 April 2021 Accepted: 21 July 2021

Published online: 03 August 2021

\section{References}

1. Ikenaka Y, Nakayama SM, Muzandu K, Choongo K, Teraoka H, Mizuno N, et al. Heavy metal contamination of soil and sediment in Zambia. Afr J Environ Sci Tech. 2010;4(11):729-39.

2. Kumar V, Parihar RD, Sharma A, Bakshi P, Sidhu GPS, Bali AS, et al. Global evaluation of heavy metal content in surface water bodies: a metaanalysis using heavy metal pollution indices and multivariate statistical analyses. Chemosphere. 2019;236:124364.

3. Yang Q, Li Z, Lu X, Duan Q, Huang L, Bi J. A review of soil heavy metal pollution from industrial and agricultural regions in China: pollution and risk assessment. Sci Total Environ. 2018;642:690-700.

4. Ghosh M, Singh S. A review on phytoremediation of heavy metals and utilization of it's by products. Asian J Energy Environ. 2005;6(4):18.

5. van der Ent A, Baker AJ, Reeves RD, Chaney RL, Anderson CW, Meech JA, et al. Agromining: farming for metals in the future? Washington DC: ACS Publications; 2015.

6. Corzo Remigio A, Chaney RL, Baker AJ, Edraki M, Erskine PD, Echevarria $G$, et al. Phytoextraction of high value elements and contaminants from mining and mineral wastes: opportunities and limitations. Plant Soil. 2020:449(1):11-37.

7. Wakeel A, Farooq M, Bashir K, Ozturk L. Micronutrient malnutrition and biofortification: recent advances and future perspectives. Plant micronutrient use efficiency. Amsterdam: Elsevier; 2018. p. 225-43.

8. Assunção AG, Schat $H$, Aarts MGM. Thlaspi caerulescens, an attractive model species to study heavy metal hyperaccumulation in plants. New Phytol. 2003;159(2):351-60.

9. Gonneau C, Noret N, Gode C, Frerot H, Sirguey C, Sterckeman T, et al. Demographic history of the trace metal hyperaccumulator Noccaea caerulescens (J. Presl and C. Presl) FK Mey, Western Europe. Mol Ecol. 2017;26(3):904-22.

10. Kozhevnikova AD, Seregin IV, Aarts MGM, Schat H. Intra-specific variation in zinc, cadmium and nickel hypertolerance and hyperaccumulation capacities in Noccaea caerulescens. Plant Soil. 2020;452(1):479-98.

11. Assunção AG, Martins PDC, De Folter S, Vooijs R, Schat H, Aarts MGM. Elevated expression of metal transporter genes in three accessions of the metal hyperaccumulator Thlaspi caerulescens. Plant, Cell Environ. 2001;24(2):217-26. 
12. van de Mortel JE, Villanueva LA, Schat H, Kwekkeboom J, Coughlan S, Moerland PD, et al. Large expression differences in genes for iron and zinc homeostasis, stress response, and lignin biosynthesis distinguish roots of Arabidopsis thaliana and the related metal hyperaccumulator Thlaspi caerulescens. Plant Physiol. 2006;142(3):1127-47.

13. Kobae Y, Uemura T, Sato MH, Ohnishi M, Mimura T, Nakagawa T, et al. Zinc transporter of Arabidopsis thaliana AtMTP1 is localized to vacuolar membranes and implicated in zinc homeostasis. Plant Cell Physiol. 2004:45(12):1749-58.

14. Gustin JL, Loureiro ME, Kim D, Na G, Tikhonova M, Salt DE. MTP1dependent $Z n$ sequestration into shoot vacuoles suggests dual roles in $\mathrm{Zn}$ tolerance and accumulation in Zn-hyperaccumulating plants. Plant J. 2009:57(6):1116-27.

15. Lin Y-F, Aarts MGM. The molecular mechanism of zinc and cadmium stress response in plants. Cell Mol Life Sci. 2012;69(19):3187-206.

16. Callahan DL, Hare DJ, Bishop DP, Doble PA, Roessner U. Elemental imaging of leaves from the metal hyperaccumulating plant Noccaea caerulescens shows different spatial distribution of Ni. Zn and Cd RSC Adv. 2016;6(3):2337-44.

17. Dinh N, van der Ent A, Mulligan DR, Nguyen AV. Zinc and lead accumulation characteristics and in vivo distribution of $\mathrm{Zn} 2+$ in the hyperaccumulator Noccaea caerulescens elucidated with fluorescent probes and laser confocal microscopy. Environ Exp Bot. 2018;147:1-12.

18. Kozhevnikova AD, Seregin I, Gosti F, Schat H. Zinc accumulation and distribution over tissues in Noccaea caerulescens in nature and in hydroponics: a comparison. Plant Soil. 2017;411(1-2):5-16.

19. van der Ent A, Spiers KM, Brueckner D, Echevarria G, Aarts MGM, Montargès-Pelletier E. Spatially-resolved localization and chemical speciation of nickel and zinc in Noccaea tymphaea and Bornmuellera emarginata. Metallomics. 2019;11(12):2052-65.

20. Towett EK, Shepherd KD, Lee DB. Plant elemental composition and portable X-ray fluorescence (pXRF) spectroscopy: quantification under different analytical parameters. X-Ray Spectrom. 2016;45(2):117-24.

21. Proctor $\mathrm{G}$, Wang $\mathrm{H}$, Larson $\mathrm{SL}$, Ballard JH, Knotek-Smith H, Waggonor $C$, et al. Rapid screening for uranium in soils using field-portable $X$-ray fluorescence spectrometer: a comparative study. ACS Earth Space Chem. 2020:4(2):211-7.

22. van der Ent A, Purwadi I, Harris HH, Kopittke PM, Przybyłowicz WJ, Mesjasz-Przybyłowicz J. Methods for visualizing elemental distribution in hyperaccumulator plants. Agromining: farming for metals. Berlin: Springer; 2021. p. 197-214.

23. Van der Ent A, Echevarria G, Baker AJ, Morel JL. Agromining: farming for metals: extracting unconventional resources using plants. Berlin: Springer; 2017.

24. Turkoglu M, Hanbay D. Recognition of plant leaves: an approach with hybrid features produced by dividing leaf images into two and four parts. Appl Math Comp. 2019;352:1-14.

25. Price CA, Symonova O, Mileyko Y, Hilley T, Weitz JS. Leaf extraction and analysis framework graphical user interface: segmenting and analyzing the structure of leaf veins and areoles. Plant Physiol. 2011;155(1):236-45.

26. Mzoughi O, Yahiaoui I, Boujemaa N, editors. Extraction of leaf parts by image analysis. In: International conference image analysis and recognition. Berlin: Springer; 2012

27. Dhondt S, Van Haerenborgh D, Van Cauwenbergh C, Merks RM, Philips W, Beemster GT, et al. Quantitative analysis of venation patterns of Arabidopsis leaves by supervised image analysis. Plant J. 2012;69(3):553-63.

28. Wu SG, Bao FS, Xu EY, Wang Y-X, Chang Y-F, Xiang Q-L, editors. A leaf recognition algorithm for plant classification using probabilistic neural network. In: 2007 IEEE international symposium on signal processing and information technology. Giza: IEEE; 2007.

29. Clarke J, Barman S, Remagnino P, Bailey K, Kirkup D, Mayo S, et al., editors. Venation pattern analysis of leaf images. In: International symposium on visual computing. Berlin, Heidelberg: Springer; 2006.

30. Cope JS, Remagnino P, Barman S, Wilkin P, editors. The extraction of venation from leaf images by evolved vein classifiers and ant colony algorithms. In: International conference on advanced concepts for intelligent vision systems. Berlin, Heidelberg: Springer; 2010.

31. Mullen RJ, Monekosso D, Barman S, Remagnino P, Wilkin P, editors. Artificial ants to extract leaf outlines and primary venation patterns. In: International conference on ant colony optimization and swarm intelligence. Berlin, Heidelberg: Springer; 2008.
32. Li YF, Zhu QS, Cao YK, Wang CL, editors. A leaf vein extraction method based on snakes technique. In: 2005 international conference on neural networks and brain. Beijing: IEEE; 2005.

33. Cerutti $G$, Tougne $L$, Vacavant $A$, Coquin $D$, editors. A parametric active polygon for leaf segmentation and shape estimation. In: International symposium on visual computing. Berlin, Heidelberg: Springer; 2011.

34. Shi W, van de Zedde R, Jiang H, Kootstra G. Plant-part segmentation using deep learning and multi-view vision. Biosys Eng. 2019;187:81-95.

35. Boogaard FP, Rongen KS, Kootstra GW. Robust node detection and tracking in fruit-vegetable crops using deep learning and multi-view imaging. Biosys Eng. 2020;192:117-32.

36. Barth R, ljsselmuiden J, Hemming J, Van Henten EJ. Synthetic bootstrapping of convolutional neural networks for semantic plant part segmentation. Comput Electron Agric. 2019;161:291-304.

37. Visscher PM, Hill WG, Wray NR. Heritability in the genomics era-concepts and misconceptions. Nat Rev Genet. 2008;9(4):255-66.

38. Kruijer W, Boer MP, Malosetti M, Flood PJ, Engel B, Kooke R, et al. Markerbased estimation of heritability in immortal populations. Genetics. 2015;199(2):379-98.

39. Bullock J, Cuesta-Lázaro C, Quera-Bofarull A, editors. XNet: A convolutional neural network (CNN) implementation for medical X-Ray image segmentation suitable for small datasets. In: Medical Imaging 2019: biomedical applications in molecular, structural, and functional imaging. San Diego: International Society for Optics and Photonics; 2019.

40. Barth R, IJsselmuiden J, Hemming J, Van Henten EJ. Data synthesis methods for semantic segmentation in agriculture: a Capsicum annuum dataset. Comput Electron Agric. 2018;144:284-96.

41. Ward D, Moghadam P, Hudson N. Deep leaf segmentation using synthetic data. arXiv preprint a rXiv:180710931; 2018.

42. Ubbens J, Cieslak M, Prusinkiewicz P, Stavness I. The use of plant models in deep learning: an application to leaf counting in rosette plants. Plant Meth. 2018;14(1):6.

43. Kang MS, Miller JD, Tai P. Genetic and phenotypic path analyses and heritability in Sugarcane 1. Crop Sci. 1983;23(4):643-7.

44. Akinwale M, Gregorio G, Nwilene F, Akinyele BO, Ogunbayo S, Odiyi A. Heritability and correlation coefficient analysis for yield and its components in rice (Oryza sativa L.). Afr J Plant Sci. 2011;5(3):207-12.

45. Wang X, Xuan H, Evers B, Shrestha S, Pless R, Poland J. High-throughput phenotyping with deep learning gives insight into the genetic architecture of flowering time in wheat. GigaScience. 2019;8(11):giz120.

46. Flood PJ, Kruijer W, Schnabel SK, van der Schoor R, Jalink H, Snel JF, et al. Phenomics for photosynthesis, growth and reflectance in Arabidopsis thaliana reveals circadian and long-term fluctuations in heritability. Plant Meth. 2016;12(1):1-14.

47. Chen D, Neumann K, Friedel S, Kilian B, Chen M, Altmann T, et al. Dissecting the phenotypic components of crop plant growth and drought responses based on high-throughput image analysis. Plant Cell. 2014;26(12):4636-55.

48. Moore CR, Gronwall DS, Miller ND, Spalding EP. Mapping quantitative trait loci affecting Arabidopsis thaliana seed morphology features extracted computationally from images. G3. 2013;3(1):109-18.

49. Purwadi I, Gei V, Echevarria G, Erskine PD, Mesjasz-Przybyłowicz J, Przybyłowicz WJ, et al. Tools for the Discovery of hyperaccumulator plant species in the field and in the herbarium. Agromining: farming for metals. Springer; 2020. p. 183-95.

50. Nkrumah PN, Echevarria G, Erskine PD, van der Ent A. Contrasting nickel and zinc hyperaccumulation in subspecies of Dichapetalum gelonioides from Southeast Asia. Sci Rep. 2018;8(1):1-15.

51. Otsu N. A threshold selection method from gray-level histograms. IEEE Trans Syst Man Cybern. 1979;9(1):62-6.

52. Gonzalez RC, Woods RE. Digital image processing. 3rd ed. Hoboken: Prentice-Hall, Inc.; 2006

53. Falconer DS. Introduction to quantitative genetics. Delhi: Pearson Education India; 1996.

\section{Publisher's Note}

Springer Nature remains neutral with regard to jurisdictional claims in published maps and institutional affiliations. 